\title{
Clave genérica para las compuestas de la cuenca del río Balsas
}

\author{
José LUIS VILLASEÑoR ${ }^{1}$
}

RESUMEN. Estimaciones actuales indican que la flora de la cuenca del río balsas incluye 131 géneros de Compositae. Se enlistan dichos géneros bajo las tribus a que pertenecen y se proporciona una clave para su identificación.

ABSTRACT. Present estimates of the flora of the river Balsas basin yield 131 genera of Compositae. The genera are listed under their corresponding tribes and a key to the genera is provided.

La cuenca del río Balsas es una depresión con dirección este-oeste ubicada en el SO de México. Incluye parte de los estados de Jalisco, Michoacán, México, Morelos, Puebla, Tlaxcala, Guerrero y Oaxaca (fig. 1).

Fisiográficamente está limitada por el Eje Neovolcánico y la Sierra Madre del Sur principalmente. Rzedowski (1978) la considera como una provincia florística, dentro de su Región Caribea, estrechamente relacionada con la Región Xerofítica Mexicana a través de su parte oriental, donde entra en contacto con la zona semiárida poblanooaxaqueña.

La mayor parte de su superficie está sometida a un clima cálido-semiseco, aunque hacia el oriente se acentúa más la condición de aridez, donde se encuentra una mayor proporción de elementos xerófilos. Asimismo, por su posición entre dos macizos montañosos de gran importancia, esta región se caracteriza por toda una serie de tipos de vegetación, influenciados conjuntamente por el clima y por la altitud, teniéndose desde matorrales xerófilos y bosques tropicales, hasta bosques de encinos y pinos e incluso pastizales alpinos por arriba del límite de la vegetación arbórea. La vegetación de esta cuenca ha sido estudiada por Miranda (1942, 1943, 1947).

La gran diversidad de condiciones ambientales dentro de esta cuenca, así como sus relaciones con las provincias florísticas circundantes, pertenecientes a dos o tres regiones fitogeográficas distintas (Rzedowski, 1978), le confieren una gran riqueza florística, tal y como se observa en muchas otras zonas tropicales de México y el mundo.

${ }^{1}$ Departamento de Botánica, Instituto de Biología, Universidad Nacional Autónoma de México, Apdo. Postal 70-367, 04510 México, D.F.

Villaseñor JL. 1987. Clave genérica para las compuestas de la cuenca del río Balsas. Boletín de la Sociedad Botánica de México 47: 65-86. 


\section{Los GÉNERos DE COMPOSITAE EN LA CUENCA DEL RÍo BALSAS}

La familia Compositae cuenta en México con uno de sus principales centros de diversificación. Rzedowski (1972, 1978a) estima que alrededor del 13\% del total de la flora de nuestro país está representada por miembros pertenecientes a esta familia. De los cerca de 1300 géneros existentes en el mundo, unos 340 están presentes en México, de los cuales 131 se encuentran en la cuenca del Balsas.

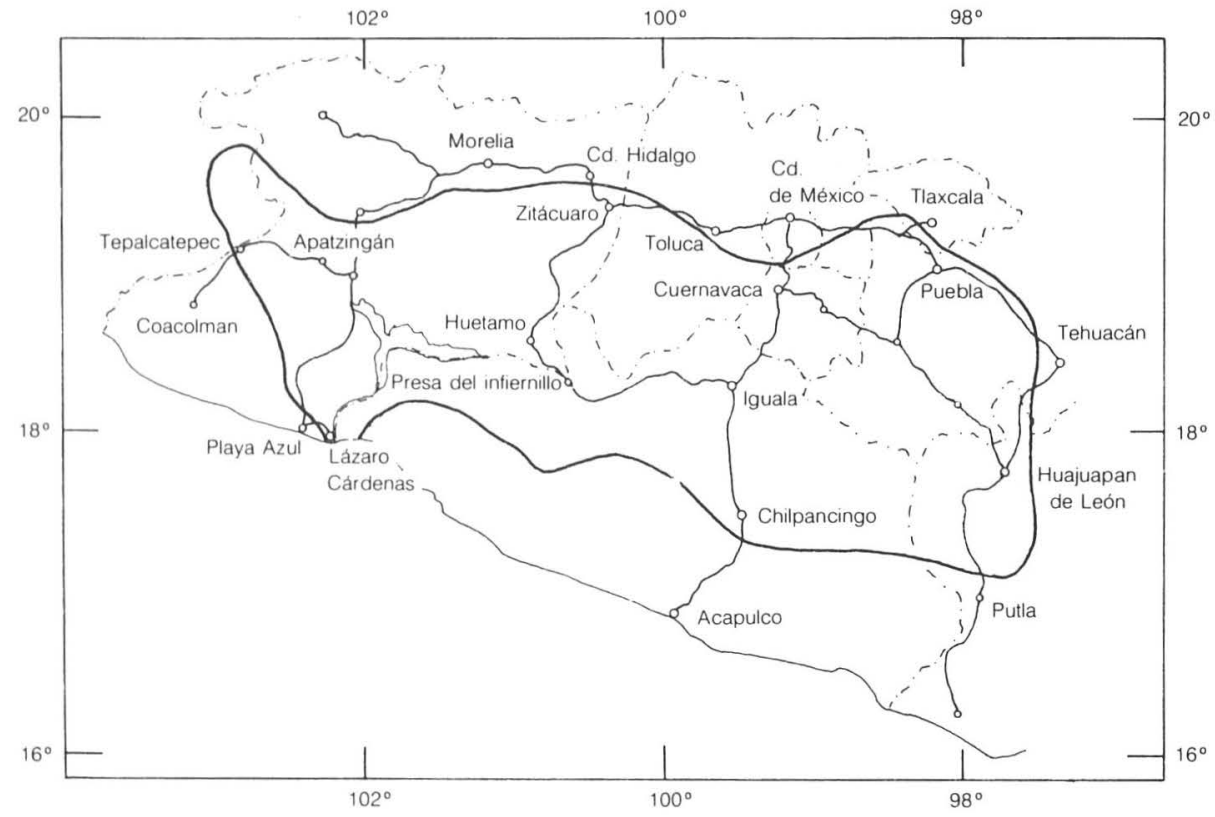

Figura 1. Mapa de la cuenca del río Balsas.

El objetivo principal de este trabajo es presentar un mecanismo que ayude en la determinación de los géneros de esta familia, los cuales se reconocen formando parte de la flora de la cuenca del Balsas, sin hacer una separación climática, regional o geográfica.

Para la recopilación del listado genérico se consultaron diversas fuentes, entre las que destacan los trabajos sobre la vegetación de la zona, el trabajo biográfico de Hinton 
y Rzedowski (1975) sobre G. B. Hinton, principal recolector de la cuenca; los datos inéditos del biólogo José Carmen Soto, quien durante varios años ha venido recolectando en muchos de los sitios visitados por Hinton, principalmente de la parte media y occidental de la cuenca; los datos sobre la parte oriental que, dentro del proyecto florístico para la zona xerófila poblano-oaxaqueña, han sido recopilados por F. Chiang y colaboradores en el Instituto de Biología de la UNAM. Sobre todo, la consulta del material depositado en el Herbario Nacional (MEXU) del Instituto de Biología de la UNAM ha sido uno de los principales recursos utilizados.

De todo lo anterior, se recopilaron 131 géneros, los cuales se distribuyen taxonómicamente en las siguientes tribus de la familia (el arreglo se hizo alfabéticamente):

\section{TRIBU ANTHEMIDEAE \\ 1. Achillea L. \\ 2. Artemisia L. \\ 3. Cotula L. \\ 4. Tanacetum L.}

\section{TRIBU ASTEREAE}

1. Achaetogeron Gray

2. Aphanostephus DC.

3. Archibaccharis Heering

4. Aster L.

5. Astranthium Nutt.

6. Baccharis L.

7. Conyza Less.

8. Erigeron L.

9. Grindelia Willd.

10. Gutierrezia Lag.

11. Gymnosperma Less.

12. Haplopappus Cass.

13. Heterotheca Cass.

14. Machaerantbera Nees

15. Xanthocephalum Willd.

TRIBU CICHORIEAE

1. Hieracium L.

2. Lactuca L.

3. Picris L.

4. Pinaropappus Less.

5. Sonchus L.

6. Taraxacum Wiggers

TRIBU CYNAREAE

1. Centaurea L.

2. Cirsium Miller

TRIBU EUPATORIEAE

1. Ageratum L.

2. Alomia Kunth

3. Barroetea Gray
4. Brickellia Ell.
5. Carminatia Moc.
6. Carphochaete Gray
7. Decachaeta DC.
8. Eupatorium L.
9. Fleischmannia Sch. Bip.
10. Hofmeisteria Walp.
11. Isocarpha R. Brown
12. Metastevia Grashoff
13. Microspermum Lag.
14. Mikania Willd.
15. Oxylobus Moc.
16. Piqueria Cav.
17. Stevia Cav.
18. Trichocoronis Gray

TRIBU HELIANTHEAE

1. Achyropappus H.B.K.

2. Acmella Rich. ex Pres.

3. Aldama La Llave \& Lex.

4. Ambrosia L.

5. Aspilia Thou.

6. Axiniphyllum Benth.

7. Bidens L.

8. Calea L.

9. Chrysanthellum L. Rich.

10. Coreopsis L.

11. Cosmos Cav.

12. Cymophora Robins.

13. Dablia Cav.

14. Delilia Spreng.

15. Desmanthodium Benth.

16. Eclipta L.

17. Eryngiophyllum Greenm.

18. Flaveria A. L. Juss.

19. Florestina Cass.

20. Flourensia DC.

21. Galeana La Llave

22. Galinsoga Ruiz \& Pav.

23. Guardiola Cerv. ex Humb. \& Bonpl. 
24. Haplocalymma Blake

25. Helenium L.

26. Helianthella Torrey \& Gray

27. Heliopsis Pers.

28. Heterosperma Cav.

29. Hymenostephium Benth.

30. Iostephane Benth.

31. Jaegeria H.B.K.

32. Jaumea Pers.

33. Lagascea Cav.

34. Lasianthaea DC.

35. Melampodium L.

36. Milleria L.

37. Montanoa Cerv.

38. Neurolaena R. Brown

39. Oteiza La Llave

40. Otopappus Benth.

41. Oxypappus Benth.

42. Oyedaea DC.

43. Parthenium L.

44. Perymenium Schrader

45. Podachaenium Benth. ex Oerst.

46. Polymnia L.

47. Rhysolepis Blake

48. Rumfordia DC.

49. Sabazia Cass.

50. Salmea DC.

51. Sanvitalia Lam.

52. Schkubria Roth

53. Sclerocarpus Jacq.

54. Selloa H.B.K.

55. Sigesbeckia L.

56. Simsia Pers.

57. Stuessya Turner \& Davies

58. Tithonia Desf. ex A. L. Juss.

59. Tridax L.

60. Trigonospermum Less.

61. Verbesina $L$.
62. Viguiera H.B.K.

63. Wedelia Jacq.

64. Xanthium L.

65. Zaluzania Pers.

66. Zexmenia La Llave \& Lex.

67. Zinnia L.

TRIBU INULEAE

1. Gnaphalium L.

2. Pluchea Cass.

3. Pseudoconyza Cuatrec.

TRIBU LIABEAE

1. Liabum Adans.

TRIBU MUTISIEAE

1. Acourtia D. Don

2. Chaptalia Vent.

3. Gochnatia H.B.K.

4. Leibnitzia Cass.

5. Onoseris DC.

6. Trixis P. Browne

TRIBU SENECIONEAE

1. Erechtites Rafin.

2. Senecio L.

TRIBU TAGETEAE

1. Chrysactinia Gray

2. Dyssodia Cav.

3. Pectis L.

4. Porophyllum Adans.

5. Tagetes L.

TRIBU VERNONIEAE

1. Elephantopus L.

2. Vernonia Schreb.

Estos 131 géneros representan el 38\% del total para México, destacando la cuenca como uno de los sitios más ricos de todo el país en elementos de esta familia. Su gran riqueza florística, el interés cada vez mayor por conocer los recursos vegetales de México y la carencia de elementos para una más fácil identificación de estos recursos, ha sido la causa principal para presentar este trabajo.

La clave aquí expuesta es completamente artificial; fue planeada tratando de eliminar, hasta donde fue posible, la difícil interpretación de caracteres micromorfológicos, los cuales se necesitan analizar previamente, para ubicar la tribu a la que pertenece el ejemplar bajo estudio, cuando se quiere identificar. Se proporciona también un glosario con la explicación de la mayoría de los términos utilizados en ella.

Esta clave está inspirada en la de Rzedowski (1978a), de la cual se han tomado muchos puntos, los cuales incluso se han utilizado casi sin cambio alguno en el texto. 


\section{Clave para la identificación de los géneros de Compositae presentes en la cuenca del río Balsas}

1. Cabezuelas homógamas, todas las flores del mismo tipo.

2. Cabezuelas liguladas; todas las flores con corola ligulada; plantas con látex.

3. Receptáculo con páleas; brácteas involucrales membranáceas, obscuras y por lo general coloreadas o manchadas en el ápice .............. Pinaropappus

3. Receptáculo sin páleas, aunque en ocasiones fimbriífero; brácteas involucrales verdosas, herbáceas.

4. Cabezuelas solitarias, largamente pedunculadas; hojas en roseta basal Taraxacum

4. Cabezuelas dispuestas en inflorescencias; hojas distribuidas en el tallo, rara vez también en roseta basal.

5. Brácteas involucrales con los márgenes espinosos; vilano de cerdas plumosas ........................................ Pis

5. Brácteas involucrales con los márgenes no espinosos; vilano de cerdas no plumosas, cuando mucho barbadas.

6. Vilano con tintes obscuros; hojas caulinares no amplexicaules Hieracium

6. Vilano blanquecino, sin tintes obscuros; hojas caulinares amplexicaules.

7. Invólucro cilíndrico o cilíndrico-ovoide, rara vez de más de $5 \mathrm{~mm}$ de

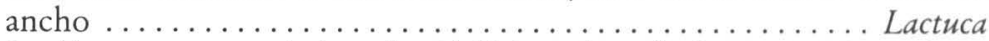

7. Invólucro campanulado o hemisférico, de más de $5 \mathrm{~mm}$ de ancho .

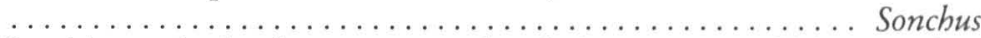

2. Cabezuelas discoides; todas las flores con corola tubular, o a veces filiforme; plantas sin látex.

8. Invólucro de $2 \mathrm{~cm}$ o más de largo; brácteas involucrales espinosas, a veces también las hojas.

9. Hojas con los lóbulos espinosos; brácteas involucrales sin los márgenes espinosos, ocasionalmente sólo las más externas ............. Cirsium

9. Hojas sin espinas; brácteas involucrales con numerosas espinas en los márge-

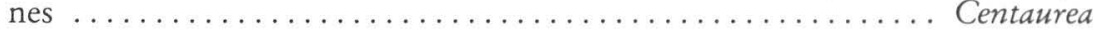

8. Invólucro de menos de $2 \mathrm{~cm}$ de largo; brácteas involucrales muy rara vez espinosas; hojas sin espinas.

10. Cabezuelas de primer orden dispuestas en glomérulos o en cabezuelas de cabezuelas (sinflorescencias).

11. Invólucro verdadero de brácteas soldadas; cabezuelas con 1 o 2 flores, agrupadas en sinflorescencias ....................... Lagascea

11. Invólucro verdadero de brácteas libres; cabezuelas con 1 o más flores agrupadas en glomérulos.

12. Aquenios con vilano de aristas .............. Elephantopus

12. Aquenios $\sin$ vilano ........................ Flaveria

10. Cabezuelas de primer orden dispuestas en cimas, corimbos, racimos, panículas, etc., nunca en glomérulos o en sinflorescencias.

13. Corolas ligera a conspicuamente bilabiadas, cuando menos las periféricas.

14. Corolas conspicuamente bilabiadas, el labio exterior trífido y el interior revoluto; plantas arbustivas ................ Trixis 
14. Corolas conspicua o inconspicuamente bilabiadas, pero sin el labio interior revoluto; hierbas anuales o perennes, rara vez arbustos.

15. Flores sólo las periféricas bilabiadas, con 3 lóbulos exteriores más largos y 2 inferiores más cortos; flores interiores con las corolas tubulares o infundibuliformes.

16. Pedúnculos glandular-pubescentes; hojas sin glándulas puntiformes ...

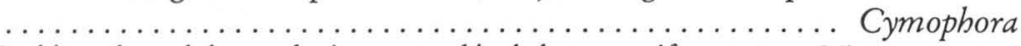

16. Pedúnculos glabros; hojas con glándulas puntiformes .. Microspermum 15. Flores todas conspicua o inconspicuamente bilabiadas.

17. Brácteas involucrales 5 o 6 ; flores 4 a 6 .

18. Aquenios sin vilano, aunque su parte apical muy suberizada; hojas de la base del tallo modificadas en brácteas; hierbas perennes

Metastevia

18. Aquenios con vilano de aristas o escamas, rara vez ausente, sin el ápice suberizado; hojas bracteiformes ausentes en la base del tallo, presentes sólo en los estolones; hierbas o arbustos ......... Stevia

17. Brácteas involucrales más de 6; flores más de 6 .

19. Hojas discoloras, con pubescencia lanosa en el envés y lirado-pinnadas; corolas con el labio exterior 4-dentado; ramas del estilo unidas...

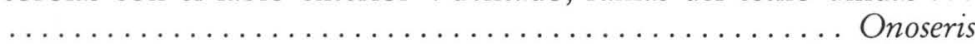

19. Hojas concoloras, glabras o pubescentes, rara vez lirado-pinnadas; corolas con el labio exterior 3-dentado o con los lóbulos de diferentes tamaños; ramas del estilo separadas.

20. Hojas coriáceas; vilano de cerdas ............... Acourtia

20. Hojas no coriáceas; vilano de escamas ........... Florestina

13. Corolas no bilabiadas, incluso las periféricas.

21. Vilano de cerdas plumosas; hierbas anuales ............... Carminatia

21. Vilano, cuando presente, no de cerdas plumosas; hierbas anuales a arbustos.

22. Plantas dioicas o polígamo-dioicas; flores estaminadas con el gineceo estéril, flores femeninas filiformes.

23. Plantas polígamo-dioicas; cabezuelas pistiladas con una o más flores hermafroditas en el centro, pero funcionalmente estaminadas

23. Plantas dioicas; cabezuelas rigurosamente unisexuales ...... Baccharis

22. Plantas monoicas o hermafroditas, no dioicas o polígamo-dioicas; flores femeninas, cuando presentes, no filiformes.

24. Cabezuelas unisexuales, las masculinas dispuestas en inflorescencias racemosas terminales y las femeninas en la base de las inflorescencias masculinas; flores femeninas sin corola, envueltas por un invólucro generalmente espinoso.

25. Invólucro de las cabezuelas femeninas generalmente con espinas ganchudas; receptáculo alargado; brácteas involucrales de las cabezuelas masculinas libres; hojas serradas o dentadas, no pinnatífidas ......

25. Invólucro de las cabezuelas femeninas generalmente con tubérculos o 
espinas no ganchudas; receptáculo plano o convexo; brácteas involucrales de las cabezuelas masculinas más o menos unidas; hojas por lo general pinnatífidas

24. Cabezuelas bisexuales; flores perfectas.

Ambrosia

26. Arbustos efusos; hojas blanco-tomentosas en el envés, de menos de $2 \mathrm{~cm}$ de largo

Gochnatia

26. Hierbas o arbustos no efusos; hojas rara vez blanco-tomentosas en el envés, de más de $2 \mathrm{~cm}$ de largo.

27. Cabezuelas con menos de 8 flores.

28. Receptáculo con páleas, éstas acrescentes en la madurez ... Montanoa

28. Receptáculo sin páleas.

29. Plantas escandentes; cabezuelas con 4 flores y 4 brácteas involucrales; vilano de 10 o más cerdas ...................... Mikania

29. Plantas no escandentes; cabezuelas con 3-8 flores y 5-10 brácteas involucrales; vilano de 8-10 cerdas, en ocasiones menos, o de escamas o ausente.

30. Cabezuelas de $2 \mathrm{~cm}$ o más de largo; aquenios $9 \mathrm{~mm}$ o más de largo, $8-10$ acostillados ..................... Carphochaete

30. Cabezuelas de menos de $2 \mathrm{~cm}$ de largo; aquenios por lo general de menos de $5 \mathrm{~mm}$ de largo, 5-acostillados.

31. Cabezuelas ovoides o campanuladas, $5 \mathrm{~mm}$ o menos de largo; aquenios $3 \mathrm{~mm}$ o menos de largo; anteras sin apéndices apicales

Piqueria

31. Cabezuelas cilíndricas a campanuladas, rara vez de menos de $5 \mathrm{~mm}$ de largo; aquenios de más de $3 \mathrm{~mm}$ de largo; anteras con apéndices apicales ...................... Stevia

27. Cabezuelas con más de 8 flores.

32. Hojas y brácteas involucrales con glándulas oleíferas lineales ........

32. Hojas y brácteas involucrales sin glándulas oleíferas lineales.

Porophyllum

33. Receptáculo con páleas.

34. Receptáculo cónico o alargado.

35. Hojas alternas ..................... Zaluzania

35. Hojas opuestas, a veces las superiores alternas.

36. Aquenios con vilano; páleas del receptáculo flexibles, delgadas.

37. Vilano de escamas; aquenios glabros ..... Ageratum

37. Vilano de cerdas o arıstas; aquenios ciliados.

38. Hierbas anuales o perennes; cabezuelas por lo general solitarias y largamente pedunculadas Acmella

38. Arbustos, en ocasiones escandentes; cabezuelas dispuestas en inflorescencias, rara vez largamente pedunculadas ..................... Salmea

36. Aquenios sin vilano; páleas del receptáculo rígidas ...... Isocarpha 
34. Receptáculo plano o convexo.

39. Hojas hastadas y rasposas al tacto en el haz...

39. Hojas no hastadas, rara vez rasposas al tacto en el haz.

Axiniphyllum

40. Páleas rígidas y acuminadas en el ápice; aquenios comprimidos Simsia

40. Páleas flexibles y redondeadas a agudas en el ápice; aquenios gruesos, rara vez comprimidos, pero entonces con los márgenes ciliados.

41. Ramas del estilo largas y clavadas, notablemente exertas de la corola.

42. Vilano de cerdas, éstas ligera a conspicuamente ensanchadas en el ápice Decachaeta

42. Vilano de escamas, éstas en ocasiones formando una corona .. Ageratum

41. Ramas del estilo no largas y clavadas, rara vez notablemente exertas de la corola.

43. Aquenios comprimidos y ciliados en los márgenes; vilano de 2 cerdas o aristas, a veces acompañadas por algunas escamas; arbustos, en ocasiones escandentes ..................... Salmea

43. Aquenios no comprimidos ni ciliados en los márgenes; vilano de 4 a muchas cerdas, aristas o escamas, a veces ausente; hierbas o arbustos no escandentes.

44. Invólucro en 2 o 3 series de brácteas subiguales .... Tridax 44. Involucro graduado, con 3 o más series de brácteas conspicuamente desiguales.

45. Hojas alternas y con frecuencia lobuladas; plantas generalmente pubescentes, con textura rugosa ..... Neurolaena

45. Hojas opuestas, al menos las inferiores, no lobuladas; plantas glabras, o si son pubescentes, rara vez brindando una textura rugosa $\ldots \ldots \ldots \ldots \ldots \ldots \ldots \ldots$ Calea

33. Receptáculo sin páleas.

46. Vilano de cerdas o aristas.

47. Ramas del estilo lineales o claviformes, obtusas en el ápice, sin pelos conspicuos.

48. Aquenios comprimidos; hojas con dientes prolongados en cerdas ....

48. Aquenios no comprimidos; hojas sin dientes prolongados en cerdas.

49. Aquenios con más de 8 costillas o nervaduras.

50. Vilano de 3 a 15 aristas, a veces también con algunas escamas; invólucro cilíndrico; aquenios de más de $9 \mathrm{~mm}$ de largo ......

Carphochaete

50. Invólucro generalmente turbinado o campanulado, rara vez cilíndrico; vilano de más de 15 cerdas, sin escamas; aquenios de menos de $7 \mathrm{~mm}$ de largo ...................................

49. Aquenios con 3 a 6 costillas o nervaduras.

51. Hojas 1 o 2 veces pinnadas y largamente pecioladas; cabezuelas sobre pedúnculos largos .................. Hofmeisteria

51. Hojas dentadas a lobuladas, pero no pinnadas; cabezuelas rara vez sobre pedúnculos largos. 


\section{CLAVE GENÉRICA PARA COMPUESTAS}

52. Cerdas del vilano más cortas que la longitud del aquenio; hojas sésiles $\ldots \ldots \ldots \ldots \ldots \ldots \ldots \ldots \ldots \ldots \ldots \ldots \ldots \ldots \ldots$ Trichocoronis

52. Cerdas del vilano más largas que la longitud del aquenio; hojas pecioladas, rara vez sésiles.

53. Parte superior de la corola pubescente, en ocasiones también glandular; cerdas del vilano por lo general 10 o menos .... Fleischmannia

53. Parte superior de la corola glabra; cerdas del vilano por lo general más

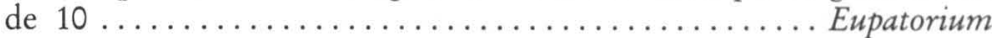

47. Ramas del estilo más anchas, rara vez lineales, agudas, apendiculadas, truncadas o peniciladas en el ápice, pero no obtusas, con pelos conspicuos.

54. Hojas coriáceas y con nervaduras prominentes; brácteas involucrales graduadas y con tintes obscuros, por lo general mucronatas .... Acourtia

54. Hojas no coriáceas, sin nervaduras prominentes; brácteas involucrales graduadas o en 1 o 2 series, rara vez con tintes obscuros, agudas, muy rara vez mucronatas.

55. Hojas opuestas .

Liabum

55. Hojas alternas o basales.

56. Vilano biseriado, la serie exterior más corta que la interior; brácteas involucrales en 3 o más series .............. Vernonia

56. Vilano uniseriado; brácteas involucrales en 1 o 2 series. Senecio

46. Vilano de escamas o ausente.

57. Vilano de escamas, éstas en ocasiones formando una corona.

58. Invólucro graduado, turbinado-campanulado, de más de $7 \mathrm{~mm}$ de largo; escamas del vilano más de 10; aquenios pubescentes ......... Jaumea

58. Invólucro en 2 a 3 series subiguales, cilíndrico-campanulado a campanulado, rara vez turbinado, de menos de $7 \mathrm{~mm}$ de largo; escamas del vilano menos de 10 o coroniforme; aquenios glabros.

59. Corolas de más de $8 \mathrm{~mm}$ de largo; hojas densamente glandular-puntea-

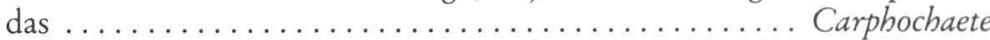

59. Corolas de $5 \mathrm{~mm}$ de largo o menos; hojas sin glándulas puntiformes, ocasionalmente unas cuantas.

60. Corolas con el tubo angosto y abruptamente expandiéndose en una garganta; hojas subcoriáceas ................. Oxylobus

60. Corolas con el tubo gradualmente pasando a una garganta poco definida; hojas firmes a membranáceas, pero no subcoriáceas Ageratum

57. Vilano ausente, aunque a veces la base de la corola simulando un vilano anular.

61. Hojas de más de $5 \mathrm{~cm}$ de largo, de contorno orbicular o palmado-pinnatífi-

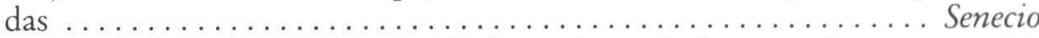

61. Hojas rara vez de más de $5 \mathrm{~cm}$ de largo, lanceoladas a ovadas, nunca orbiculares o palmado-pinnatífidas.

62. Cabezuelas con menos de 15 flores; brácteas involucrales 5 o menos Flaveria

62. Cabezuelas con más de 15 flores; brácteas involucrales más de 10 Alomia

1. Cabezuelas heterógamas; flores periféricas pistiladas o neutras, flores del disco hermafroditas, en ocasiones masculinas por aborción del gineceo. 
63. Cabezuelas sésiles, dispuestas en glomérulos, secundariamente dispuestas en corimbos o panículas; brácteas involucrales lageniformes, envolviendo las flores pistiladas; flores del disco con el gineceo estéril .................. Desmanthodium

63. Cabezuelas por lo general pedunculadas, a veces sésiles y dispuestas en glomérulos, pero entonces las brácteas involucrales no lageniformes y sin envolver las flores pistiladas; flores del disco con el gineceo fértil o estéril.

64. Flores periféricas con la corola filiforme o ausente.

65. Hierbas diminutas, no mayores de $5 \mathrm{~cm}$ de alto, pubescentes; flores periféricas sin corola, flores centrales hermafroditas pero funcionalmente estaminadas

65. Hierbas o arbustos de más de $10 \mathrm{~cm}$ de alto, pubescentes o glabras; flores periféricas con las corolas filiformes, flores centrales hermafroditas, fértiles o funcionalmente estaminadas.

66. Brácteas involucrales escariosas, en ocasiones sólo los márgenes; plantas por lo general pubescentes.

67. Hierbas anuales o perennes, lanosas; hojas sésiles y con frecuencia decurrentes; vilano de cerdas ................. Gnaphalium

67. Hierbas perennes o arbustos no lanosos, en ocasiones seríceos; hojas rara vez sésiles, pero no decurrentes; vilano ausente .... Artemisia

66. Brácteas involucrales herbáceas o cartáceas, no escariosas; plantas glabras o pubescentes.

68. Plantas polígamo-dioicas; cabezuelas femeninas con algunas flores hermafroditas en el centro, aunque funcionalmente estaminadas .... Archibaccharis

68. Plantas no polígamo-dioicas; cabezuelas con todas las flores del disco hermafroditas.

69. Hierbas escapíferas; hojas todas basales y con el envés blanco-to-

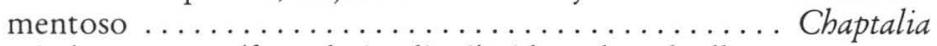

69. Hierbas no escapíferas; hojas distribuidas sobre el tallo, rara vez con el envés blanco-tomentoso.

70. Arbustos o hierbas seríceas; corolas con tintes rosados; invólucro dispuesto en 3 o más series de brácteas ....... Pluchea

70. Hierbas rara vez seríceas; corolas blanquecinas a amarillentas, rara vez purpurinas, pero entonces el invólucro con 1 o 2 series de brácteas.

71. Invólucro en 1 o 2 series de brácteas; vilano de cerdas capilares suaves; hojas amplexicaules .......... Erechtites

71. Invólucro en 3 o más series de brácteas; vilano de cerdas capilares firmes; hojas no amplexicaules.

72. Plantas glandular-pubescentes; anteras insertas; hojas por lo general ovadas y conspicuamente dentadas, de más de $1 \mathrm{~cm}$ de ancho ............... Pseudoconyza

72. Plantas no glandular-pubescentes; anteras por lo general exertas; hojas lanceoladas o pinnatífidas, rara vez de más de $1 \mathrm{~cm}$ de ancho ................ Conyza 
64. Flores periféricas radiadas, es decir, con la corola ligulada o ligulado-bilabiada. 73. Flores radiadas o discoides conspicua a inconspicuamente bilabiadas.

74. Hierbas escapíferas; hojas discoloras, el envés blanco-tomentoso; flores del disco bilabiadas, flores radiadas con o sin lóbulos en la base de la lígula; vilano de cerdas capilares escabrosas o barbadas.

75. Aquenios vilosos; cabezuelas erectas; pedúnculos bracteados; flores radiadas bilabiadas, con 2 lóbulos pequeños en la base de la lígula Leibnitzia 75. Aquenios papilosos; cabezuelas péndulas, rara vez erectas; pedúnculos rara vez bracteados; flores radiadas no bilabiadas ............ Chaptalia

74. Hierbas no escapíferas, las hojas distribuidas sobre el tallo; hojas concoloras; flores del disco tubulares, flores radiadas bilabiadas, con 1 o 2 lóbulos pequeños en la base de la lígula; vilano de cerdas o escamas fimbriadas o plumosas,

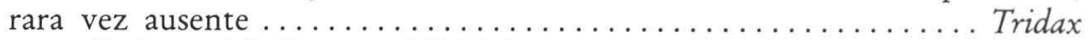

73. Flores radiadas o del disco no bilabiadas.

76. Hojas, brácteas involucrales o ambas estructuras con glándulas oleíferas puntiformes o lineales.

77. Hojas con uno o varios pares de cerdas en la base; ramas del estilo cortas y $\sin$ apéndices apicales .......................... Pectis

77. Hojas sin cerdas en la base; ramas del estilo largas y con apéndices apicales. 78. Brácteas involucrales en 2 series; invólucro a menudo con calículo

78. Brácteas involucrales en 1 serie; invólucro sin calículo. Dyssodia 79. Arbustos o sufrútices; vilano de cerdas o aristas ... Chrysactinia 79. Hierbas anuales o perennes; vilano de escamas ........ Tagetes 76. Hojas y brácteas involucrales sin glándulas oleíferas.

80. Brácteas involucrales con los márgenes escariosos; ramas del estilo truncadas y coronadas por un penacho de pelos; vilano ausente o coroniforme. 81. Hojas 2 a 3-pinnatífidas, de contorno oblongo; vilano ausente .... Achillea 81. Hojas 1 o 2-pinnatífidas, de contorno ovado; vilano coroniforme . Tanacetum

80. Brácteas involucrales sin los márgenes escariosos; ramas del estilo con apéndices apicales, rara vez truncadas y peniciladas, pero entonces los aquenios con vilano de cerdas.

82. Brácteas involucrales en 2 series, la serie externa verdosa, herbácea, la serie interna membranácea, pardusca.

83. Hojas alternas.

84. Hierbas anuales no mayores de $20 \mathrm{~cm}$ de alto; cabezuelas de menos de $7 \mathrm{~mm}$ de diámetro ........... Chrysanthellum

84. Hierbas perennes, rara vez anuales, de más de $20 \mathrm{~cm}$ de alto; cabezuelas de más de $7 \mathrm{~mm}$ de diámetro ....... Coreopsis

83. Hojas opuestas.

85. Aquenios de las flores del disco lineales y rostrados; aquenios de las flores radiadas más anchos y no rostrados Heterosperma

85. Aquenios de las flores del disco iguales a los de las flores radia- 
das, en ocasiones los de las flores radiadas estériles.

86. Aquenios tetragonales y con un surco angosto en cada cara, por lo general rostrados; filamentos de las anteras pubescentes ............ Cosmos

86. Aquenios rara vez tetragonales, pero sin un surco angosto en cada cara; filamentos de las anteras glabros.

87. Hierbas robustas con las hojas de más de $10 \mathrm{~cm}$ de largo, al menos las basales; brácteas involucrales exteriores carnosas, arrugadas cuando secas; raíces tuberosas; cabezuelas por lo general de más de $4 \mathrm{~cm}$ de diámetro

Dablia

87. Hierbas rara vez robustas, en ocasiones sufrútices o arbustos; hojas de menos de $10 \mathrm{~cm}$ de largo; brácteas involucrales exieriores no carnosas, lisas cuando secas; raíces no tuberosas; cabezuelas por lo general de menos de $4 \mathrm{~cm}$ de diámetro.

88. Aquenios comprimidos, los de las flores del disco alados o con los márgenes engrosados y vilosos; vilano de aristas glabras o antrorsamente barbadas, en ocasiones ausente ................. Coreopsis

88. Aquenios rara vez comprimidos, por lo general tetragonales, sin alas o márgenes engrosados o vilosos; vilano de aristas retrorsamente bar-

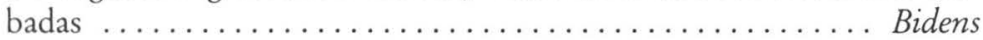

82. Brácteas involucrales en una o más series, todas verdosas, herbáceas y de la misma textura, o en ocasiones secas en la base, pero no membranáceas.

89. Receptáculo sin páleas.

90. Aquenios de las flores del disco sin vilano o con vilano de escamas, éstas en ocasiones prolongándose como aristas.

91. Hojas alternas o basales.

92. Flores radiadas pocas e inconspicuas, no mayores en tamaño que las flores del disco; plantas glutinosas ............. Gymnosperma

92. Flores radiadas pocas a numerosas, conspicuas, más grandes que las flores del disco; plantas rara vez glutinosas.

93. Cabezuelas con el receptáculo globoso a cónico; flores radiadas reflexas en la madurez; invólucro en 2 series, la serie externa reflexa o pátula en antesis; hojas sésiles o decurrentes sobre el tallo; tallo frecuentemente alado .................... Helenium

93. Cabezuelas rara vez con el receptáculo globoso o cónico, pero entonces las lígulas y la serie externa de brácteas involucrales erectas en antesis; hojas rara vez decurrentes sobre el tallo; tallo no alado. 94. Flores radiadas 1 a 3, 1-3 mm de largo; hojas pinnada o bipinnadamente divididas en segmentos lineales ...... Schkubria 94. Flores radiadas más de 3 , de más de $3 \mathrm{~mm}$ de largo; hojas no divididas, cuando mucho lobuladas.

95. Flores radiadas amarillas.

96. Corola de las flores del disco abruptamente ampliada, algo acopada; receptáculo reticulado, glabro .......

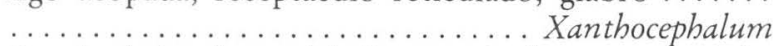
96. Corola de las flores del disco gradualmente ampliada, 
clavada o infundibuliforme; receptáculo alveolado, pubescente Gutierrezia 95. Flores radiadas blancas a violáceas, nunca amarillas

97. Brácteas involucrales dispuestas en 3 a 5 series; aquenios de las flores del disco prismáticos o columnares ................. Aphanostephus

97. Brácteas involucrales dispuestas en 2 a 3 series; aquenios de las flores del disco comprimidos, rara vez prismáticos o columnares.

98. Flores radiadas más de $40 \ldots \ldots \ldots \ldots \ldots \ldots$. . . . . . . . . .

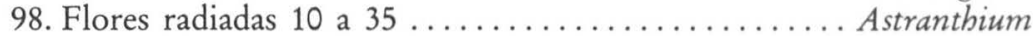

91. Hojas opuestas, al menos las inferiores.

99. Aquenios con vilano.

100. Hojas simples; flores radiadas 6 o más; escamas del vilano terminando en un ápice aristiforme .................... Oxурарри

100. Hojas divididas en segmentos lineales; flores radiadas por lo general 5; escamas del vilano obtusas en el ápice ............. Achyropappus

99. Aquenios sin vilano.

101. Aquenios de las flores radiadas con los márgenes curvados, suberosos y

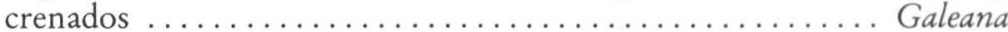

101. Aquenios de las flores radiadas nunca con los márgenes curvados, suberosos o crenados.

102. Hierbas anuales glutinosas; hojas de más de $5 \mathrm{~cm}$ de largo; invólucro globoso, no comprimido .................. Milleria

102. Hierbas anuales no glutinosas; hojas de menos de $5 \mathrm{~cm}$ de largo; invólucro fuertemente comprimido, la bráctea situada más hacia afuera muy agrandada ....................... Delilia

90. Aquenios de las flores del disco con vilano de cerdas o aristas.

103. Invólucro en 1 o 2 series subiguales.

104. Flores radiadas más de 40 , nunca amarillas .............. Erigeron

104. Flores radiadas menos de 20 , principalmente amarillas ....... Senecio 103. Invólucro en 3 o más series graduadas.

105. Hojas opuestas, blanco-tomentosas en el envés ............ Liabum

105. Hojas alternas, no blanco-tomentosas en el envés.

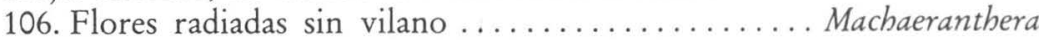

106. Flores radiadas con vilano.

107. Vilano de 2 a 15 cerdas o aristas, éstas en ocasiones algo paleáceas ................................ Grindelia

107. Vilano de elementos más numerosos.

108. Plantas hirsutas; vilano de los aquenios de las flores del disco en 2 series, la serie interna más larga que la serie externa Heterotheca

108. Plantas no hirsutas; vilano de los aquenios de las flores del disco en una serie, rara vez 2 o más, iguales o desiguales. 109. Flores radiadas amarillas, rara vez violáceas; aquenios rollizos a fusiformes ............... Haplopappus

109. Flores radiadas blancas o violáceas, nunca amarillas; aquenios algo comprimidos .............. Aster 
89. Receptáculo con páleas.

110. Flores radiadas sin tubo definido, sésiles y persistentes sobre los aquenios.

111. Flores radiadas 5; hojas alternas; cabezuelas de menos de $7 \mathrm{~mm}$ de diámetro, incluyendo lígulas ........................... Parthenium

111. Flores radiadas más de 5; hojas opuestas; cabezuelas de más de $7 \mathrm{~mm}$ de diámetro, incluyendo lígulas.

112. Aquenios de las flores radiadas con vilano de 3 aristas. Sanvitalia 112. Aquenios de las flores radiadas sin vilano o formado por una sola arista. 113. Hojas principalmente dentadas y pecioladas; brácteas involucrales dispuestas en 1 a 3 series subiguales .......... Heliopsis

113. Hojas principalmente enteras o lobuladas, sésiles o corto-pecioladas; brácteas involucrales dispuestas en 3 a muchas series graduadas ................................. Zinnia

110. Flores radiadas con tubo definido, no sésiles sobre los aquenios, decíduas.

114. Plantas escapíferas o subescapíferas.

115. Flores radiadas fértiles; hojas todas basales, no panduriformes ni rasposas al tacto en el haz ................... Eryngiophyllum

115. Flores radiadas estériles; hojas basales panduriformes y algo rasposas al tacto en el haz, en ocasiones presentes también algunas caulinares más pequeñas ........................ Iostephane

114. Plantas no escapíferas ni subescapíferas, las hojas esparcidas sobre los tallos. 116. Flores del disco hermafroditas pero funcionalmente masculinas por aborción del ovario, sus aquenios estériles y translúcidos.

117. Hojas alternas; flores del disco desprendiéndose del receptáculo como un todo ........................ Parthenium

117. Hojas opuestas; flores del disco desprendiéndose individualmente del receptáculo.

118. Brácteas involucrales interiores envolviendo completamente los aquenios de las flores radiadas y formando con ellos un solo cuerpo, rugosas y con frecuencia tuberculadas o con pequeñas espinas ...................... Melampodium

118. Brácteas involucrales interiares sin envolver completamente los aquenios de las flores radiadas a manera de formar un solo cuerpo, fácilmente separables.

119. Invólucro cilíndrico; brácteas involucrales parduscas; lígulas inconspicuas ............... Guardiola

119. Invólucro hemisférico o campanulado; brácteas involucrales verdosas; lígulas conspícuas.

120. Invólucro de menos de $8 \mathrm{~mm}$ de diámetro; flores radiadas menos de $10 \ldots$. . Trigonospermum

120. Invólucro de más de $8 \mathrm{~mm}$ de diámetro; flores radiadas más de $10 \ldots \ldots \ldots \ldots$. Polymnia

116. Flores del disco hermafroditas y fértiles, sus aquenios pardos o negros, no translúcidos.

121. Hojas alternas. 
122. Cabezuelas grandes, por lo general de $5 \mathrm{~cm}$ o más de diámetro, incluyendo lígulas; pedúnculos huecos justo debajo de las cabezuelas; brácteas involucrales anchas, dispuestas en 1 a 3 series ....................... Tithonia

122. Cabezuelas de menos de $5 \mathrm{~cm}$ de diámetro; pedúnculos no huecos debajo de las cabezuelas; brácteas involucrales en 1 a muchas series, anchas o angostas. 123. Arbustos resinosos; aquenios densamente pubescentes; vilano de escamas angostas $y$ agudas ........................... Flourensia

123. Hierbas anuales a arbustos no resinosos; aquenios glabros a pubescentes, pero si son densamente pubescentes, entonces con las escamas del vilano redondeadas y fimbriadas.

124. Cabezuelas de menos de $7 \mathrm{~mm}$ de diámetro, incluyendo lígulas; plantas de menos de $20 \mathrm{~cm}$ de alto ............... Chrysanthellum

124. Cabezuelas de más de $7 \mathrm{~mm}$ de diámetro, incluyendo lígulas; plantas de más de $20 \mathrm{~cm}$ de alto.

125. Hojas densamente lanosas en el envés, rara vez de más de $3 \mathrm{~cm}$

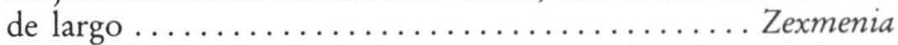

125. Hojas, sí lanosas en el envés, entonces de más de $3 \mathrm{~cm}$ de largo, pero rara vez con alguno de estos dos caracteres.

126. Aquenios de las flores del disco sin vilano.

127. Aquenios comprimidos, frecuentemente alados .... ........................... Verbesina

127. Aquenios gruesos, no alados.

128. Flores radiadas fértiles .......... Zaluzania

128. Flores radiadas estériles ............ Viguiera

126. Aquenios de las flores del disco con vilano.

129. Aquenios alados, comprimidos ........ Verbesina

129. Aquenios no alados, gruesos o rara vez comprimidos

130. Invólucro urceolado en la madurez; brácteas involucrales esclerosadas en la madurez, difíciles de romper y cubiertas con pubescencia blanquecina y crespa .................... Stuessya

130. Invólucro campanulado a cilíndrico en la madurez; brácteas involucrales rara vez esclerosadas en la madurez, por lo general con la base endurecida y la punta herbácea, sin pubescencia blanquecina crespa.

131. Páleas envolviendo completamente los aquenios, más o menos transversalmente rugosas Rhysolepis

131. Páleas rara vez envolviendo completamente los aquenios, sin rugosidades transversales ....................... Viguiera

121. Hojas opuestas, al menos las inferiores.

132. Cabezuelas grandes, por lo general de $5 \mathrm{~cm}$ o más de diámetro, incluyendo lígulas; pedúnculos huecos justo debajo de las cabezuelas ........ Tithonia 
132. Cabezuelas de menos de $5 \mathrm{~cm}$ de diámetro, incluyendo lígulas; pedúnculos no huecos debajo de las cabezuelas.

133. Aquenios completamente envueltos por las páleas y formando un solo cuerpo con ellas; hierbas anuales.

134. Páleas maduras más o menos gruesas, rígidas y fibrosas, generalmente con la superficie tuberculada; corolas de las flores del disco con 5 nervaduras

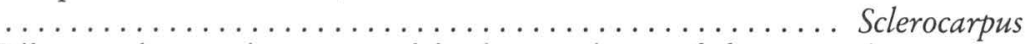

134. Páleas maduras más o menos delgadas, cartáceas o fofas, generalmente con la superficie arrugada; corolas de las flores del disco con 10 nervaduras

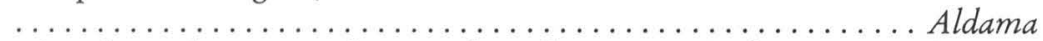

133. Aquenios abrazados o envueltos por las páleas, pero sin formar un solo cuerpo con ellas, fácilmente separables; hierbas anuales a arbustos.

135. Brácteas involucrales 5; hierbas anuales ............ Haplocalymma

135. Brácteas involucrales más de 5; hierbas anuales a arbustos.

136. Brácteas involucrales interiores envolviendo los aquenios de las flores periféricas.

137. Brácteas involucrales todas similares ........... Jaegeria

137. Brácteas involucrales exteriores distintas en forma y tamaño de las interiores.

138. Hierbas anuales con las lígulas de menos de $3 \mathrm{~mm}$ de ancho; brácteas involucrales por lo general glandulosas ...

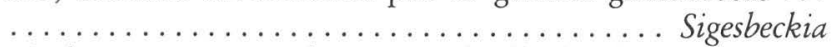

138. Hierbas perennes o arbustos con las lígulas de más de $3 \mathrm{~mm}$ de ancho; brácteas involucrales glabras o pubescentes, pero no glandulosas .................... Rumfordia

136. Brácteas involucrales interiores sin envolver los aquenios de las flores periféricas.

139. Aquenios con una constricción en el ápice para formar un cuello. 140. Flores radiadas fértiles .................Wedelia 140. Flores radiadas estériles .................. Aspilia

139. Aquenios no constrictos en el ápice, rara vez con un pequeño pico donde se asienta el vilano.

141. Aquenios alados, cuando menos en el sitio de inserción del vilano.

142. Flores radiadas amarillas, flores del disco púrpuras; hojas basales 4 a 5 veces más largas que las superiores ......................... Helianthella

142. Flores todas amarillas; hojas basales y caulinares no marcadamente diferentes.

143. Invólucro conspicuamente graduado, en más de 4 series; vilano de aristas y escamas Otopappus

143. Invólucro de brácteas subiguales, en 1 a 3 series; vilano exclusivamente de cerdas o aristas.

144. Vilano de más de 2 cerdas o aristas; arbustos, generalmente escandentes...... Oyedaea 
144. Vilano de 2 aristas; hierbas perennes a arbustos, muy rara vez escandentes

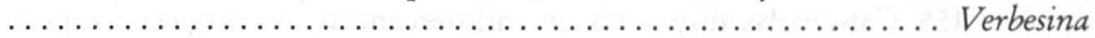

141. Aquenios no alados, rara vez con los márgenes engrosados o vilosos.

145. Hojas hastadas, rasposas al tacto; vilano ausente .......... Axiniphyllum 145. Hojas no hastadas, rara vez rasposas al tacto; vilano ausente o presente.

146. Receptáculo cónico a columnar; aquenios de las flores del disco comprimidos y con frecuencia ciliados en los márgenes .......... Acmella

146. Receptáculo plano o convexo; aquenios de las flores del disco rara vez comprimidos, pero entonces con los márgenes no ciliados.

147. Aquenios dimórficos, los de las flores del disco lineales y estirados en un pico, los de las flores radiadas más anchos y sin pico; hierbas anuales con las hojas pinnadamente partidas ....... Heterosperma

147. Aquenios de las flores radiadas y del disco similares; hojas rara vez pinnadamente partidas.

148. Flores radiadas fértiles.

149. Hojas basales simulando una roseta, más grandes que las superiores, sésiles y espatuladas; flores radiadas blancas en su cara adaxial, por lo general rosadas a purpurinas en su cara abaxial .............................. Selloa

149. Hojas rara vez basales y simulando una roseta, pero entonces las plantas con flores radiadas amarillas.

150. Flores radiadas más de 20 , inconspicuas, de menos de

$2 \mathrm{~mm}$ de largo; flores del disco más de 40 . Eclipta

150. Flores radiadas menos de 15 , conspicuas, rara vez de menos de $2 \mathrm{~mm}$ de largo; flores del disco menos de 40, rara vez más.

151. Hojas ampliamente ovadas a suborbiculares, con los márgenes angulado-lobulados, grandes, hasta $30 \mathrm{~cm}$ de largo y ancho, pubescentes; flores radiadas blancas, $8-15 \mathrm{~mm}$ de largo... Podachaenium

151. Hojas no como las anteriores, rara vez de $30 \mathrm{~cm}$ de largo y pubescentes; flores radiadas ocasionalmente blancas, pero entonces de menos de $10 \mathrm{~mm}$ de largo.

152. Vilano ausente.

153. Flores radiadas blancas en su cara adaxial, rosadas a purpurinas en su cara abaxial .................... Sabazia

153. Flores radiadas amarillas, rara vez blancas, pero entonces sin la cara abaxial rosada o purpurina.

154. Invólucro graduado, en 3 o más series ................ Calea

154. Invólucro de brácteas subiguales, en 1 a 3 series. 
155. Cabezuelas solitarias, largamente pedunculadas. .......... Jaegeria 155. Cabezuelas dispuestas en inflorescencias, no largamente pedunculadas

152. Vilano presente.

\section{Galinsoga}

156. Flores radiadas blancas en su cara adaxial, rosadas a purpurinas en su cara

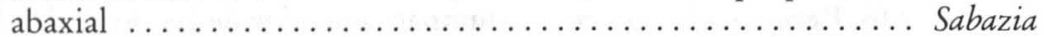

156. Flores radiadas amarillas, rara vez blancas, pero entonces sin la cara abaxial rosada o purpurina.

157. Vilano de aristas fácilmente caedizas.

158. Aristas no insertas sobre un pico o cuello en el ápice del aquenio; flores radiadas por lo general 8; páleas no aquilladas en su cara abaxial .......................... Oteiza

158. Aristas insertas sobre un pico o cuello en el ápice del aquenio; flores radiadas 5 a 12; páleas aquilladas en su cara abaxial ... .............................. Perymenium

157. Vilano de cerdas, aristas o escamas no fácilmente caedizas.

159. Vilano de aristas y escamas ............... Lasianthaea

159. Vilano formado exclusivamente por cerdas, por aristas o por escamas.

160. Invólucro graduado, en 3 o más series ......... Calea 160. Invólucro de brácteas subiguales, en 1 a 3 series .......

148. Flores radiadas neutras o pistiladas pero estériles.

Galinsoga

161. Flores radiadas blancas; páleas conspicuamente acrescentes en la madurez; aquenios sin vilano; arbustos o árboles ........................

161. Flores radiadas amarillas; páleas no acrescentes en la madurez; aquenios con o sin vilano; hierbas anuales a arbustos.

162. Aquenios fuertemente comprimidos.

163. Páleas rígidas, persistentes; aquenios sin los márgenes blanquecinos; hojas basales y caulinares no marcadamente diferentes.... Simsia

163. Páleas de textura suave, cayendo con los aquenios, éstos con los márgenes blanquecinos; hojas basales 4 a 5 veces más largas que las superiores ........................... Helianthella

162. Aquenios gruesos, rara vez ligeramente comprimidos.

164. Invólucro urceolado en la madurez; brácteas involucrales esclerosadas en la madurez, difíciles de romper y cubiertas con pubescencia blanquecina y crespa ....................... Stuessya

164. Invólucro campanulado a cilíndrico en la madurez; brácteas involucrales rara vez esclerosadas en la madurez, por lo general con la base endurecida y la punta herbácea, sin pubescencia blanquecina crespa. 165. Páleas envolviendo completamente los aquenios, más o menos transversalmente rugosas ................ Rhysolepis

165. Páleas rara vez envolviendo completamente los aquenios, sin rugosidades transversales.

166. Invólucro rara vez de más de $7 \mathrm{~mm}$ de largo; aquenios algo 
comprimidos; brácteas involucrales herbáceas completamente; vilano de escamas

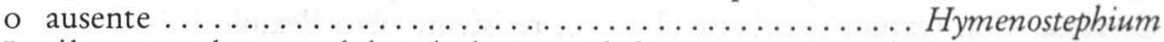
166. Invólucro por lo general de más de $7 \mathrm{~mm}$ de largo; aquenios más o menos engrosados; brácteas involucrales por lo general endurecidas en la base y adelgazándose en un ápice lineal herbáceo; vilano de aristas y escamas, ocasionalmente ausente ..

\section{GLOSARIO}

Abaxial: Dorsal; envés de la hoja.

Acrescente: Todo órgano que continúa creciendo después de formado, como las páleas en Montanoa.

Acuminado: Apice adelgazado gradualmente hasta formar una punta.

Adaxial: Ventral; cara o lado que se orienta hacia el eje; haz de la hoja.

Agudo: Con los márgenes formando un ángulo agudo en el ápice.

Ala: Prolongación laminar a los lados de algunos aquenios.

Amplexicaule: Que abraza al tallo.

Antesis: Período de floración durante el cual ocurre la polinización.

Antrorso: Que se dirige hacia arriba o hacia adelante.

Anular: En forma de anillo o círculo.

Apéndice: Porción estéril del estambre, ubicada por arriba de las anteras; es una prolongación del tejido conectivo.

Aquenio: Fruto seco e indehiscente, por lo general pequeño, con una sola semilla no fusionada al pericarpo. El aquenio deriva de un ovario súpero, en tanto que el fruto de las Compositae proviene de un ovario ínfero, por lo que más bien es una Cipsela (Aquenio derivado de un ovario ínfero).

Aquillado: Carinado, como el fondo de un barco.

Arista: Apéndice o prolongación en forma de cerda rígida, en ocasiones barbado.

Barbado: Que tiene pelos muy pequeños, a manera de barbas.

Bilabiada: Flor con corola zigomórfica, en la cual se pueden distinguir un labio superior o exterior y otro inferior o interior, o los lóbulos de la corola son manifiestamente de diferente tamaño, o, en el caso de las flores radiadas, además de la porción loriforme (lígula), se observa uno o dos labios inferiores en la parte superior del tubo, opuestos al limbo.

Bisexual: Con los dos sexos presentes y funcionales en la misma flor.

Bráctea involucral: Cada uno de los elementos, por lo general foliáceos, que rodean la cabezuela.

Cabezuela: Inflorescencia básica o de primer orden, característica de las Compositae, constituida por un invólucro de brácteas rodeando a un grupo de flores insertas sobre un receptáculo.

Calículo: Conjunto de brácteas involucrales más externas que difieren notablemente de las demás, por ser mucho más pequeñas.

Cartácea: Con textura de papel, por lo general no de color verde.

Cerda: Apéndice o elemento capilar o filiforme, más o menos flexible. 
Clavado, claviforme: En forma de clava, es decir, engrosado hacia su parte superior y más delgado en su parte inferior.

Concolora: Monofaciada, del mismo color en el haz y en el envés.

Coriácea: Con textura semejante al cuero, resistente pero flexible.

Corona: Conjunto de escamas del vilano fusionadas, semejando una corona.

Crenado: Ondeado, someramente dentado, con dientes curvos u obtusos.

Decídua: Que cae después de un cierto tiempo, como las hojas de los árboles caducifolios. Decurrente: Que se prolonga hacia abajo.

Desnudo: Receptáculo desprovisto de páleas o cualquier otro elemento, además de las flores.

Disco, flor del: Flores, por lo general tubulares o bilabiadas, dispuestas hacia el interior de la cabezuela, después de las flores radiadas en una cabezuela radiada, u ocupando todo el receptáculo en las cabezuelas discoides. Por lo general son hermafroditas, o masculinas por aborción del ovario.

Discoide, cabezuela: Cabezuela desprovista de flores radiadas, conteniendo sólo flores del disco.

Discolora: Bifaciada, de diferente color en el haz y en el envés.

Doble: Invólucro en el cual existen dos tipos de brácteas con textura, a veces también la forma, diferentes, sin que existan elementos con características intermedias.

Efuso: Intrincado, con varios tallos o ramas ampliamente desparramadas.

Escabroso: Aspero o rugoso al tacto, por la presencia generalmente de pelos cortos y duros. Escama: Elemento del vilano de forma laminar, a manera de una pequeña paja.

Escandente: Trepador, pero sin la ayuda de estructuras especializadas.

Escapifero: Que tiene sus flores sobre un pedúnculo áfilo, por lo general en una planta acaule con sus hojas dispuestas en roseta basal.

Escariosa: De textura seca y membranosa, con frecuencia translúcida.

Esclerosado: Endurecido como una piedra.

Espatulado: De forma de espátula.

Exerta: Con los estambres proyectándose o asomándose afuera de la corola.

Filiforme: Flores pistiladas con las corolas tubulares muy angostadas.

Fimbriado, fimbriifero: Con flecos, dividido en lacinias finas.

Fofa: Blanda, más o menos esponjosa.

Fusiforme En forma de huso, es decir, angostándose en ambos sentidos a partir de una parte media más ancha.

Garganta: Parte de la corola que se intercala entre el tubo y el limbo.

Glabro: Lampiño, sin ningún tipo de indumento.

Glomérulo: Inflorescencia con las flores por lo general sésiles y apiñadas densamente, más o menos globosa.

Glutinoso: Víscido, pegajoso.

Graduado: Invólucro en el que las brácteas se disponen en varias series, las externas más cortas que las internas.

Hastada: Con forma de punta de flecha pero con dos lóbulos basales proyectándose en ángulo recto.

Heterógama: Cabezuela en la que se presentan dos o más tipos de flores en cuanto a la distribución de los sexos.

Hirsuto: Con tricomas largos, rígidos y erectos. 
Homógama: Cabezuela en la que todas las flores son del mismo tipo en cuanto a la distribución de los sexos.

Infundibuliforme: Con forma de embudo, el tubo gradualmente ensanchándose hacia arriba, insensiblemente pasando al limbo.

Inserta: Incluída, no prominente; con los estambres sin proyectarse de la corola. Invólucro: Conjunto de brácteas que rodean la cabezuela simulando un cáliz.

Lageniforme: En forma de botella, con la base hinchada y la parte superior más angosta. Ligulada, cabezuela: Cabezuela exclusivamente constituida de flores con corola ligulada. Ligulada, corola: Corola con el limbo laminar (loriforme), es decir, de forma larga y estrecha como una correa, por lo general bisexual y 5-dentada en el ápice.

Limbo: Parte de la corola extendida o más ancha, no tubular.

Lineal: Largo y angosto, con los lados casi paralelos.

Lirado: Con forma de lira, es decir, con un lóbulo terminal agrandado y lóbulos inferiores más pequeños.

Membranácea: Semejante a una membrana, con textura apergaminada.

Mucronata: Terminando abruptamente en una punta corta y aguda o espiniforme.

Neutra, flor: Flor asexuada, a menudo conteniendo un ovario estéril, pero sin androceo o ramas del estilo; sin ningún sexo funcional.

Oblongo: Más largo que ancho y con los lados casi paralelos.

Oleifera: Que contiene aceite.

Ovado, ovoide: Aovado, como un huevo de gallina.

Pálea: Bráctea generalmente escariosa, semejante a una pajita, que se encuentra sobre el receptáculo asociada con las flores.

Paleáceo: Provisto de páleas.

Panduriforme: De forma de violín o de guitarra.

Papiloso: Con protuberancias muy pequeñas a manera de granos.

Pátulo: Patente, extendido, formando un ángulo casi recto con respecto al eje.

Penicilado: Semejante a un pincel.

Perfecta: Hermafrodita o bisexual.

Plumosa: Como una pluma, es decir, con pelos finos laterales.

Polígamo-dioica: Con dos tipos de individuos, unos masculinos o estaminados exclusivamente y otros, con las cabezuelas, además de las flores femeninas o pistiladas, con unas cuantas flores masculinas centrales.

Radiada, cabezuela: Cabezuela constituida por flores radiadas en la periferia y flores del disco hacia el centro.

Radiada, flor: Flor con corola ligulada, pistilada o neutra, por lo general 2-3-dentada en el ápice y dispuesta hacia la periferia de la cabezuela radiada.

Receptáculo: Superficie donde se ubican las flores en una cabezuela.

Reflexo: Encorvado abruptamente hacia abajo o hacia atrás.

Retrorso: Reflexo, doblado o volteado hacia atrás o hacia abajo.

Rollizo: Cilindráceo, terete.

Rostro: Pico.

Sinflorescencia: Cabezuela de segundo órden o cabezuela de cabezuelas, constituida por un conjunto de cabezuelas, por lo general unifloras, con el invólucro verdadero fusionado, secundariamente rodeadas por otro involúcro de brácteas libres.

Sésil: Flor que carece de tubo, principalmente las flores radiadas. 
Seríceo: Sedoso, con aspecto de seda; cubierto de pelos aplicados, finos y suaves. Tubular, corola: Corola generalmente actinomorfa, con un tubo y un limbo conspicuos. Truncado: Pareciendo cortado transversalmente en su extremo.

Tuberculado: Provisto de nudosidades o abultamientos a manera de tubérculos.

Tubo: Parte tubular de la corola.

Turbinado: Obcónico, inversamente cónico; semejante a un trompo.

Unisexual: Con un solo sexo; sólo estaminado o sólo pistilado.

Urceolado: Semejante a una urna o una olla.

Vilano: Conjunto de estructuras (aristas, cerdas, corona, escamas, etc.) ubicadas en el ápice del aquenio en la posición donde debería estar el cáliz.

Viloso: Con pelos largos y suaves.

AgradeCIMIENTOS. Muchas personas del Herbario Nacional revisaron y utilizaron la clave para probar su utilidad, por lo cual les estoy muy agradecido. A los doctores Fernando Chiang, Mario Sousa y T.P. Ramamoorthy, así como a los M. en C. Emily Lott y Francisco González Medrano, les agradezco sus críticas y sugerencias. En forma muy especial, vayan mis agradecimientos al Dr. Jerzy Rzedowski, de la Escuela Nacional de Ciencias Biológicas, por sus atinadas observaciones y comentarios, pero sobre todo, al biólogo José Carmen Soto, quien me facilitó sus datos inéditos, producto de varios años de trabajo de campo, para la elaboración de este trabajo.

\section{LITERATURA CITADA}

Hinton, J. y J. Rzedowski. 1975. George B. Hinton, explorador botánico en el Sudoeste de México. Anales Esc. Nac. Ci. Biol. 21(1-4):1-114.

Miranda, F. 1942. Estudios sobre la vegetación de México. III. Notas generales sobre la vegetación del SO del estado de Puebla, especialmente de la zona de Itzocan de Matamoros. Anales Inst. Biol. Univ. Nac. México 13 (2):417-450.

.1943. Estudios sobre la vegetación de México. IV. Algunas características de la vegetación y de la flora en la zona de Acatlán, Puebla. Anales Inst. Biol. Univ. Nac. México 14(2):407-421.

1947. Estudios sobre la vegetación de México. V. Rasgos de la vegetación en la Cuenca del Río de las Balsas. Revista Soc. Mex. Hist. Nat. 8:95-114.

RZEDOwSKI, J. 1972. Contribuciones a la fitogeografía florística e histórica de México. III. Algunas tendencias en la distribución geográfica y ecológica de las Compositae mexicanas. Ciencias (México) 27:123-132. 1978. Vegetación de México. Ed. Limusa. México. 432 p.

1978a. Claves para la identificación de los géneros de la familia Compositae en México. Acta Ci. Potosina 7:5-145. 